\title{
EFFECT OF THERMAL CYCLING ON THE TENSILE BEHAVIOR OF CF/AL FIBER METAL LAMINATES
}

\author{
Muhammad Farhan Noor', Riffat Asim Pasha', Aneela Wakeel', Muhammad Ali Nasir ${ }^{1}$, Yasir Bilal' \\ 1 University of Engineering and Technology, MS Metallurgy and Materials Engineering, 47080 Taxila, Pakistan, \\ e-mails: farhannoor1188@gmail.com, asim.pasha@uettaxila.edu.pk, aneela.wakeel@uettaxila.edu.pk, ali. \\ nasir@uettaxila.edu.pk, yasirbilal22@gmail.com
}

Received: 2017.05 .15 Accepted: 2017.08.01 Published: 2017.09.03

\begin{abstract}
The objective of this research work was to estimate the effect of thermal cycling on the tensile behavior of CARALL composites. Fiber metal laminates (FMLs), based on 2D woven carbon fabric and 2024-T3 Alclad aluminum alloy sheet were manufactured by pressure molding technique followed by hand layup method. Before fabrication, aluminum sheets were anodized with phosphoric acid to produce a micro porous alumina layer on surface. This microporous layer is beneficial to produce a strong bond between the metal and fiber surfaces in FMLs. The effect of thermal cycling (-65 to $+70^{\circ} \mathrm{C}$ ) on the tensile behavior of $\mathrm{Cf} / \mathrm{Al}$ based FML was studied. Tensile strength was increased after 10 thermal cycles, but it was decreased slightly to some extent after 30 and 50 thermal cycles. Tensile modulus also show similar behavior as that of tensile strength.
\end{abstract}

Keywords: Composite material, aluminum, anodizing process, carbon fiber, thermal cycling, tensile strength.

\section{INTRODUCTION}

Thermal cycling is the most important effect in space. The international space station undergoes about 175,000 thermal cycles from -125 to $+125^{\circ} \mathrm{C}$ rotating inside and outside of earth during its 30 year life span [14]. The difference of coefficient of thermal expansion generates large interfacial stresses between the fiber and matrix during thermal cycling. Thermal stress and matrix outgassing are produced because of thermal cycling giving rise to the composite's interfacial de-bonding and loss of mass [4]. Composites achieved consideration for satellite applications about two decades ago, where dimensional stability was in serious demand due to their contact with thermal fluctuations while orbiting the earth [8]. To evaluate the effect of significant fatigue factors on the mechanical behavior of composites, knowledge of what happens to the materials when exposed to ecological conditions, i.e. tem- perature variation and ultraviolet radiation etc. is of prime importance.

The fibers and matrix contract, or relax, as per their coefficients of thermal expansion during thermal cycling. Temperature variations build stress at the interface which causes change in fiber orientation and debonding [1]. This phenomenon causes a severe problem of bond breakage between the constituents, by creating cracks or making the existing smaller cracks bigger still, and the failure of composite occurs $[3,7,10]$.

Humidity affects the process of degradation. The association of metals and moisture observes corrosion phenomenon. It can be diminished by applying a protective layer on the surface of the material. In humid environments, epoxies absorb moisture by diffusion process. The FML composites very slowly absorb the moisture due to the outer aluminum layers as compared to polymer composites The interface between aluminum and fiber may be targeted for moisture degradation in 
FMLs. Due to hygrothermal conditioning the mechanical properties are reduced by FML related bonding and resin matrix plasticization [2].

Min Zhao [19] studied the different ranges of thermal cycling treatments and their effect on the mechanical properties of squeeze casted fabricated $\mathrm{AlNp} / \mathrm{Al}$ composites. The cycling ranging was between room temperature and 160, 230, \& $356^{\circ} \mathrm{C}$, holding for 2 hours at a higher temperature, and for 15 minutes at lower temperatures. It was found that the tensile strength was increased by 49 - 54\%, yield strength increased by $71.1-75.7 \%$, and elastic limit was increased by $70.9-79.2 \%$, after the cycling process, when compared with the die casting condition. The increase in strength was due to the combined effect of thermal cycling and the change in manufacturing processes used [9]. Li Daguang's study found that in Cf/Al composites, the bending modulus was increased at the start of thermal cycling to 5 cycles and then it was decreased when it reached 50 thermal cycles in the range of -196 to $120^{\circ} \mathrm{C}$ due to the generation of micro cracks at the interface. The amount of dislocations increased with the increase of thermal cycles decreasing the strength [4].

Qi Yu [18] investigated the thermal cycling effect on the properties of carbon/ bismaleimide composites of aerospace applications. The temperature range given was +140 to $-140^{\circ} \mathrm{C}$ with a holding time of 10 minutes, a maximum of 300 cycles were applied to the specimens. It was found that the thermal stresses and interfacial debonding were reduced due to vacuum thermal cycling. The tensile strength was reduced by up to $9 \%$ in the first 100 cycles then there was no effect. Flexural strength and ILSS were increased by 8 \& $9.6 \%$ within the first 50 cycles and then reduced by $7 \& 7.7 \%$ respectively due to matrix outgassing and interfacial debonding.

Yu Gao [5] studied the vacuum thermocycling effect on M40J/AG-80 composite's physical properties. The temperature range was +140 to $-180^{\circ} \mathrm{C}$ and with a holding time of $10 \mathrm{~min}-$ utes at both temperatures for a certain number of cycles. It was found that the tensile strength was decreased when the number of thermal cycles were increased up to 50 then it became constant. Bend strength was increased to 40 thermal cycles, and then its value decreased up to $100 \mathrm{cy}-$ cles, becoming constant after that. ILSS was first decreased and then it started to be increased. It was due to the interface debonding and the increase in density of epoxy matrix.
The young's modulus of composites decreases significantly by increasing the number of cycles due to external stresses $[6,13,16]$. No obvious defect or delamination is shown in aluminum-lithium alloy based fiber metal laminates after 1000 cycles. The tensile and flexural strengths of FMLs increased after thermal fatigue cycles [9]. Different temperature ranges exposed to the same material gives different values of strength $[11,15]$.

The aim of the current research work is to discuss the thermal cycling effect on the mechanical properties of $\mathrm{Cf} / \mathrm{Al}$ fiber metal laminates (FMLs). To manufacture the laminates, surface treatments like mechanical, chemical and electrochemical treatments are to be applied to metal sheets prior to adhesive bonding. The tensile properties of manufactured laminates are to be tested before and after thermal cycling (up to 50 cycles) between -65 and $+70^{\circ} \mathrm{C}$.

\section{EXPERIMENTAL}

\section{Materials and methods}

The material was a fiber metal laminate (FML) consisting of 2 layers of 2D woven carbon fiber, reinforced in between two $1.0 \mathrm{~mm}$ thick, phosphoric acid anodized [17], aluminum 2024-T3 alloy sheets. The laminates were manufactured by hand lay-up technique, using epoxy resin (Araldite LY 5052 and Aradur 5052 from Huntsman Advanced Materials), in the form of plates [12]. The laminates were cured for 4 to 6 days at room temperature, followed by oven curing at $50^{\circ} \mathrm{C}$ for 20 hours. The EDS analysis of specimen surface of 2024-Aluminum alloy is shown in Figure 1.

\section{Preparation of specimens}

Specimens were cut with a dimension of 170 $\times 25 \mathrm{~mm}$, using Meta Cut M250 machine, from the manufactured plates, following ASTM D3039 for tensile tests. After the polishing of specimens by emery polishing paper, their mass and dimensions were measured, and each specimen was labelled. The specimen is shown in Figure 2.

\section{Thermal cycling process}

Thermal cycling was attained in TEST-EQUITY model 115A temperature chamber machine, to check its effect on the tensile strength of FML specimens. The temperature chamber used in this research work is shown in Figure 3. 

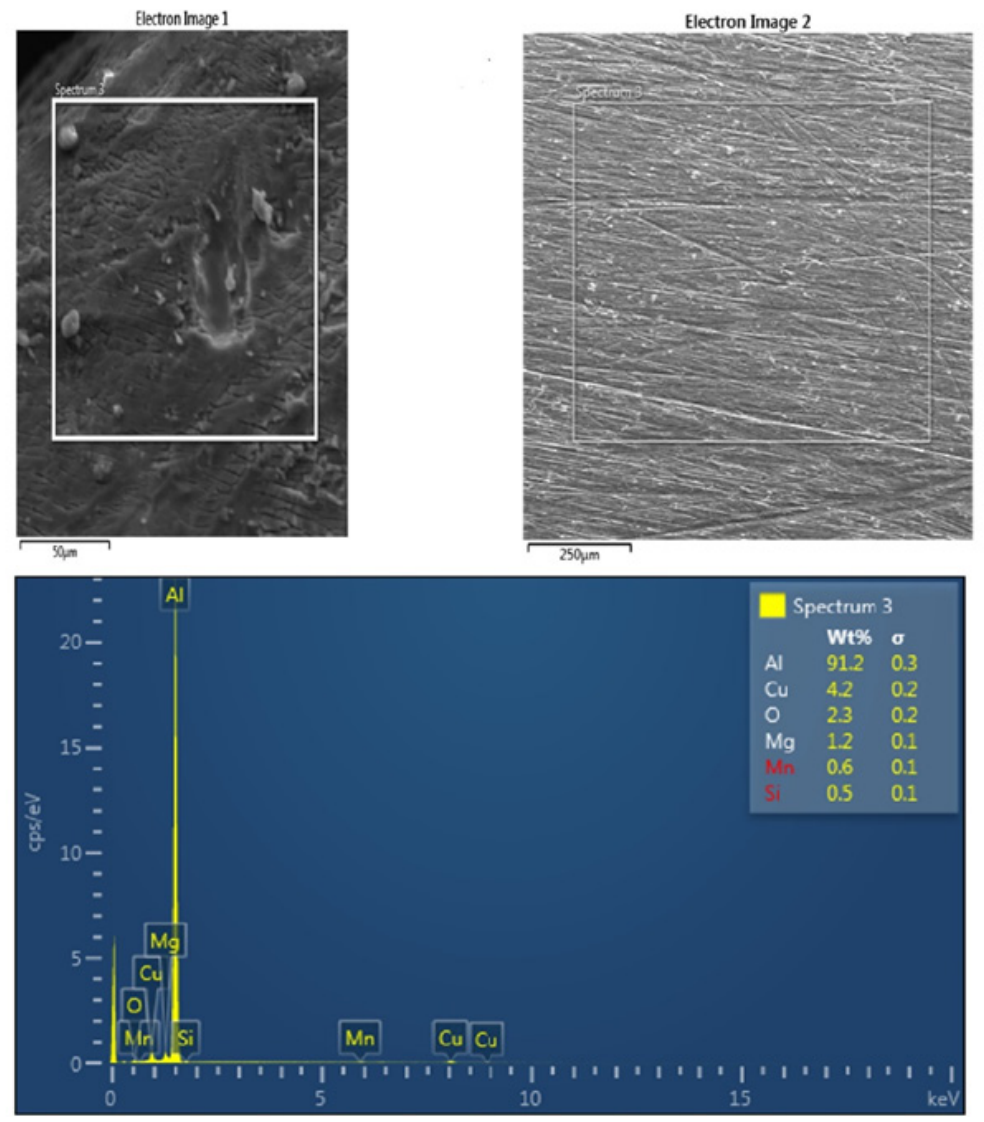

Fig. 1. EDS analysis of 2024-aluminum alloy

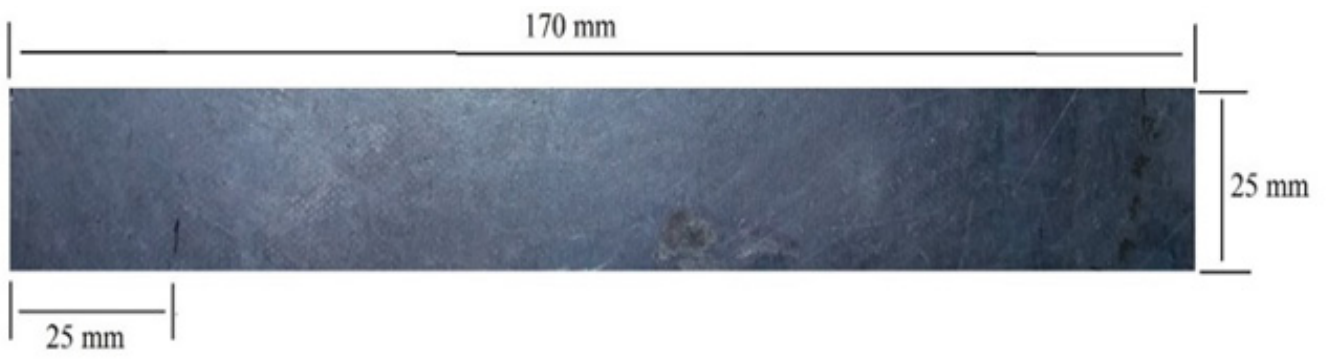

Fig. 2. Fiber metal laminate specimen prepared for tensile testing

The applied temperature profile is shown in Figure 4. In this profile, one thermal cycle was in the range of $-65^{\circ} \mathrm{C}$ to $+70^{\circ} \mathrm{C}$ with a soaking time of 1 hour and 45 minutes at each temperature, completing one thermal cycle in 5 hours and 25 minutes. The procedure for all the specimens is described as following.

- Soaking in cold conditions $\left(-65^{\circ} \mathrm{C}\right)$ for 1 hour and 45 minutes.

- Soaking in hot conditions $\left(+70^{\circ} \mathrm{C}\right)$ for 1 hour and 45 minutes.

- A set of three specimens was added to the cycling chamber, after a successive number of thermal cycles, so that the cycling of all specimens completes at the same time.

- These thermally cycled specimens were tensile tested.

- This process of thermal cycling was repeated for 10,30 , and 50 cycles.

\section{Tensile testing}

To find out the tensile strength of CARALL composites, the tensile tests were conducted on MTS 810 machine per ASTM D-3039 at ambient temperature $\left(25^{\circ} \mathrm{C}\right)$. The crosshead speed giv- 


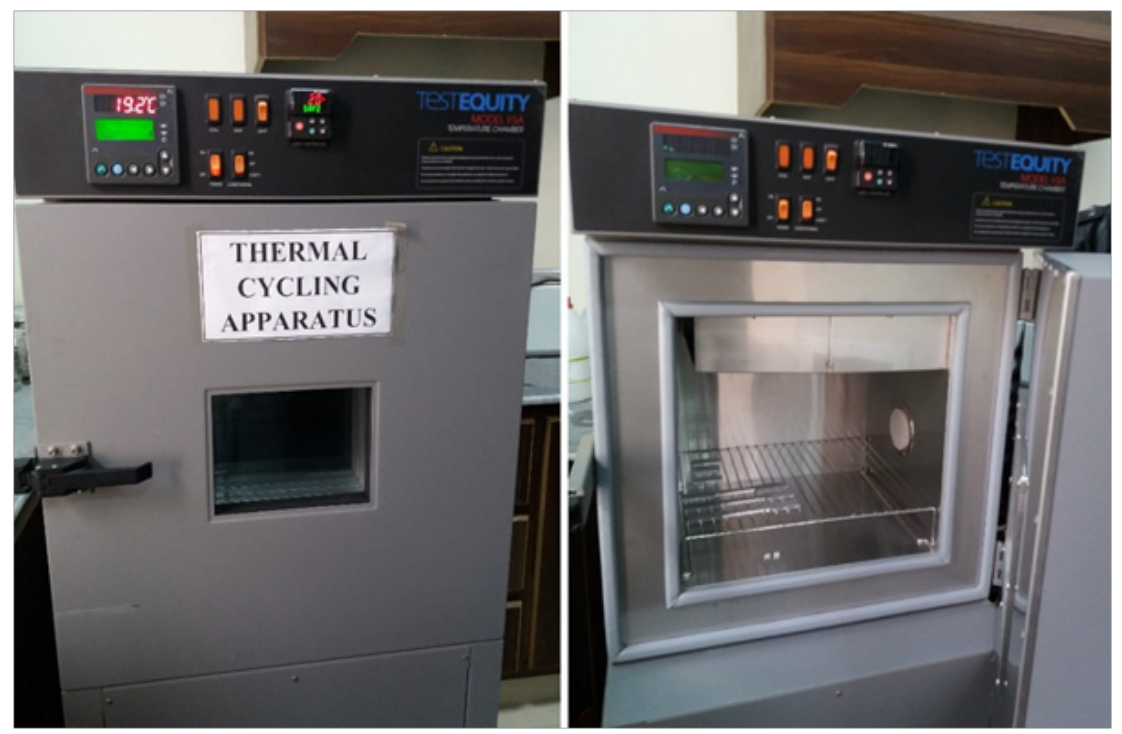

Fig. 3. Thermal cycling apparatus TESTEQUITY 115A

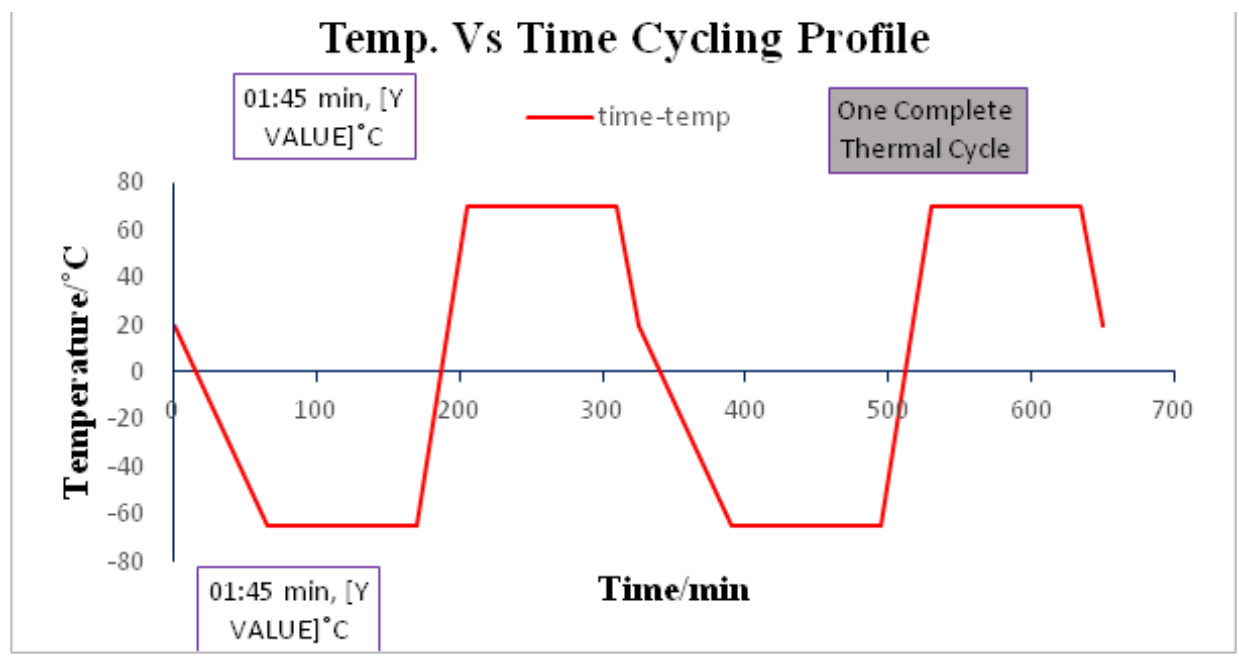

Fig. 4. Temperature vs time profile of thermal cycle

en during this tensile test was $2 \mathrm{~mm} / \mathrm{min}$. Three specimens of each set were tested and the tensile properties were calculated.

\section{RESULTS AND DISCUSSION}

\section{Microstructure of matrix al 2024-t3 sheet}

After anodization of Al 2024-T3 plate, the microstructure of the surface was examined. On Al-2024 $\mathrm{T} 3$ alclad sheet, an irregular layer of aluminum oxide was found, which inhibits the adhesive properties of metallic and non-metallic materials during their contact. The thickness of porous $\mathrm{Al}_{2} \mathrm{O}_{3}$ layer is enlarged by increasing the time of anodizing process, which may cause adverse effects on adhesion properties.

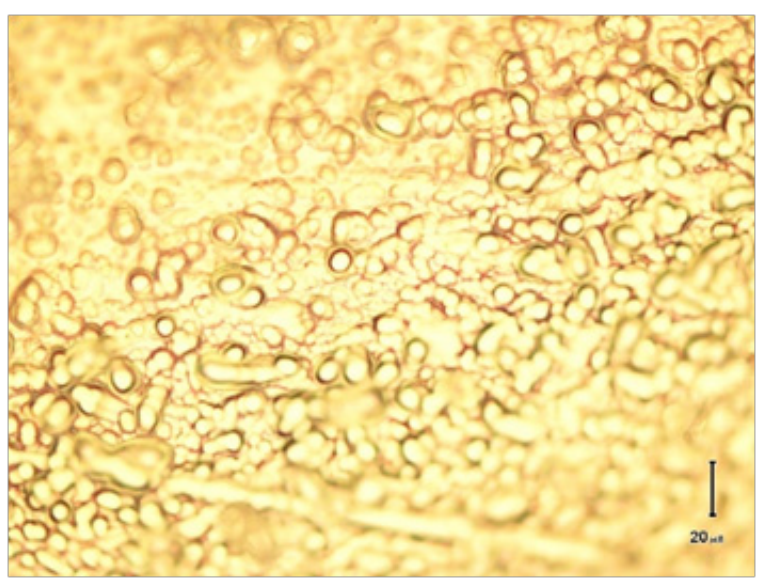

Fig. 5. Porous $\mathrm{Al}_{2} \mathrm{O}_{3}$ oxide layer and spherical grown patterns of $\mathrm{Al}_{2} \mathrm{O}_{3}$ (Metallurgical Optical Microscope) 


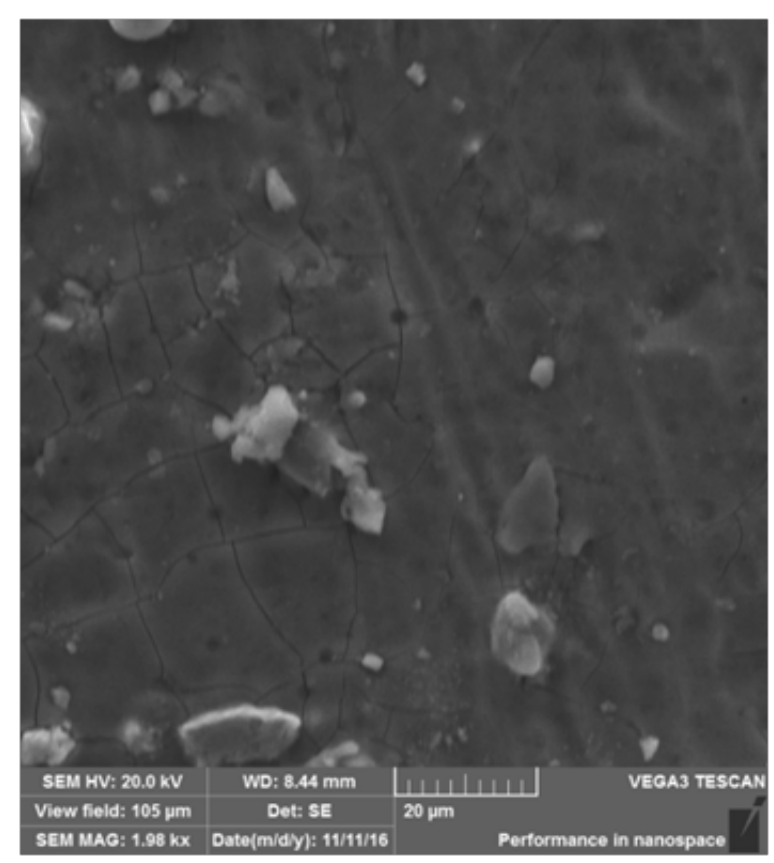

Fig. 6. Pores visible on anodized sheet (Scanning Electron Microscope)

The microstructures observed by Metallurgical Optical Microscope and Scanning Electron Microscope is shown in Figure 5 and Figure 6 respectively.

\section{Tensile properties}

The stress strain curves for $\mathrm{Al} / \mathrm{CF}$ based fiber metal laminates without thermal cycling and after different thermal cycles are shown in Figure 7.

It is clear to see from all curves that all specimens show linear trend at the start. Both metal and fiber layers show elastic behavior in this linear part. Linearity of the curve then vanishes beyond a transition point. This happens due to yielding of the metal. After crossing the transition point, curves of almost all the laminates show linearity once again. This is the effect of reinforcing fibers. One more thing of note was that Al face sheet of laminates do not fail even after their yield point is crossed. This behavior is credited to reinforcing fibers which boost the mechanical properties of the laminate $[6,7]$. A small amount of humidity was observed at lower temperatures but then was almost completely discarded at higher temperatures during cycling. The corrosion phenomenon was also eliminated due to the formation of a protective layer during anodization [2]. At the start of thermal cycling, the epoxy resin used for the bonding of metal and woven fibers was further cured and the strength of fiber metal laminate increased. After a

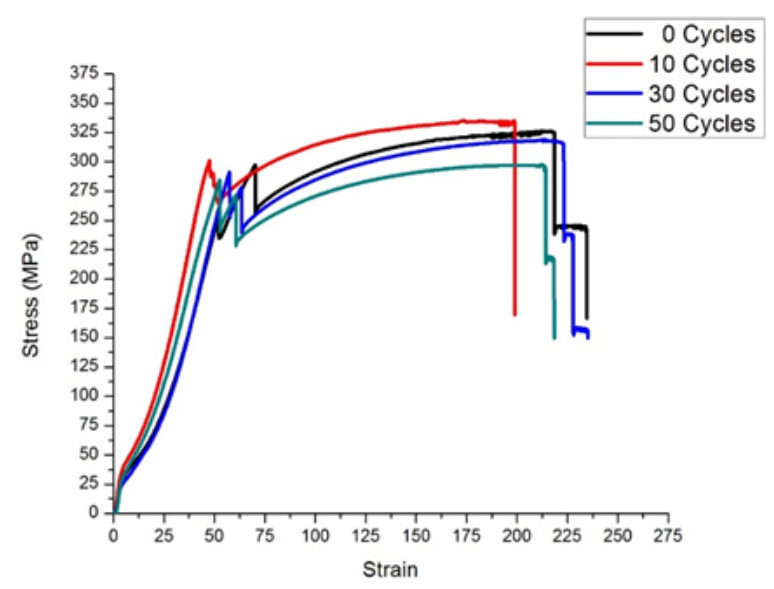

Fig. 7. Tensile stress-strain diagrams after 10, 30 and 50 cycles and without thermal cycling

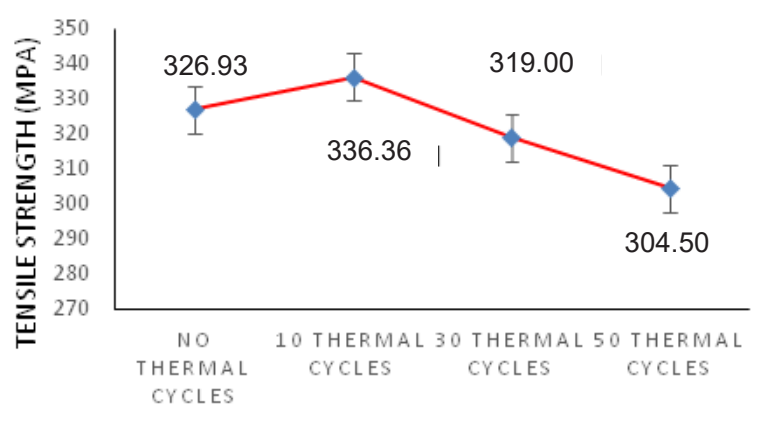

Fig. 8. Tensile Strength of FMLs after different number of Thermal Cycles (0, 10, 30 and 50)

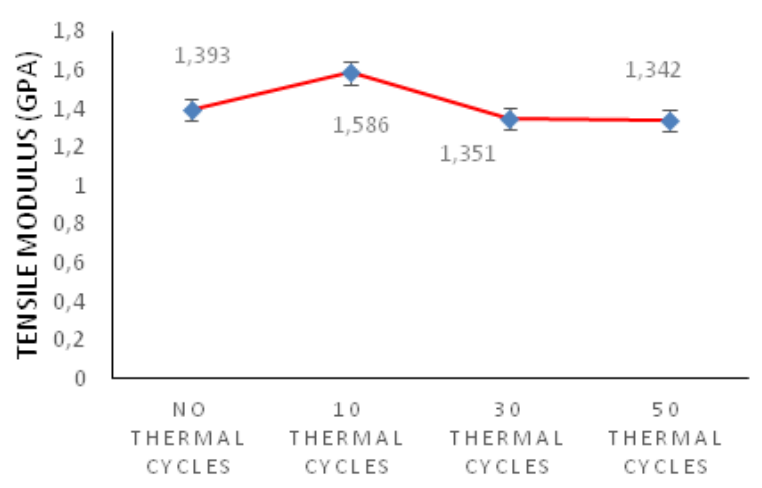

Fig. 9. Tensile Modulus of FMLs after different number of Thermal Cycles (0, 10, 30 and 50)

certain number of cycles, the resin started to decompose slightly, producing cracks and decreasing the strength of the laminates [5, 18].

The tensile strength of each laminate after different cycling treatment was calculated. It was found that it shows tensile strength of $326.93 \mathrm{MPa}$ of the original laminate without any exposure 
to thermal cycling. After ten thermal cycles, its tensile strength becomes $336.36 \mathrm{MPa}$ with an increase of $2.88 \%$ with respect to initial value [19]. After thirty thermal cycles, its tensile strength becomes $319 \mathrm{MPa}$ with a decrease of $2.43 \%$ with respect to initial value.

After fifty thermal cycles, its tensile strength becomes $304.5 \mathrm{MPa}$ with a decrease of $6.86 \%$ with respect to initial value [4]. The behavior of tensile strength after a different number of thermal cycles is shown in Figure 8. Tensile modulus were also calculated and it shows a similar trend as that of tensile strength. It was calculated to be 1.393 , $1.586,1.351, \& 1.342 \mathrm{GPa}$ after $0,10,30$ and 50 thermal cycles respectively. Its behavior is illustrated in Figure 9. From all discussions, thermal cycling is a vast and complex field that needs constant research efforts to study the various aspects of composite materials required in space applications.

\section{CONCLUSIONS}

In current research work, the effect of thermal cycling on tensile behavior of fiber metal laminates was experimentally examined. The matrix used was phosphoric acid anodized Al 2024-T3 sheet, with the reinforcement of 2D woven carbon fiber, using Araldite 5052/Aradur 5052 epoxy resin as an adhesive. The thermal cycling range was -65 to $+70^{\circ} \mathrm{C}$ with a soaking time of 1 hour and 45 minutes at both temperatures. The number of thermal cycles performed were 10,30, and 50 . It is concluded that thermal cycling resulted in varying effects on $\mathrm{Al} / \mathrm{CF}$ based fiber metal laminates. The tensile strength and tensile modulus were increased by $2.88 \%$ after 10 thermal cycles, and then decreased continuously after 30 and 50 thermal cycles by 2.43 , and $6.86 \%$ respectively. This is because epoxy resins further cure during the first few cycles and then start to decompose on further thermal cycles. This propagates the voids and transforms them into cracks when exposed to a larger numbers of thermal cycles. Humidity is also one reason for the decrease of tensile strength values. After 10 cycles and up to a large number of cycles due to slightly weakening the aluminum and fiber interfaces.

\section{Acknowledgements}

The authors highly acknowledge the University of Engineering and Technology, Taxila for their funding and support during this re- search work. Special thanks to Engr. Rana Waqas Ayoub and Engr. Naeem Jaan Khattack for their support during sample manufacturing and material testing.

\section{REFERANCES}

1. Asghar, W., et al., Investigation of fatigue crack growth rate in CARALL, ARALL and GLARE. Fatigue \& Fracture of Engineering Materials \& Structures, 2017.

2. Botelho, E.C., et al., A review on the development and properties of conti-nuous fiber/epoxy/aluminum hybrid composites for aircraft structures. Materials Research, 2006. 9(3): p. 247-256.

3. da Costa, A.A., et al., The effect of thermal cycles on the mechanical properties of fibermetal laminates. Materials \& Design, 2012. 42: p. 434-440.

4. Daguang, L., et al., Effect of thermal cycling on the mechanical properties of $\mathrm{Cf} / \mathrm{Al}$ composites. Materials Science and Engineering: A, 2013. 586: p. 330-337.

5. Gao, Y., et al., Effect of vacuum thermo-cycling on physical properties of unidirectional M40J/AG80 composites. Composites Part B: Engi-neering, 2005. 36(4): p. 351-358.

6. Grammatikos, S.A., et al., Thermal cycling effects on the durability of a pultruded GFRP material for off-shore civil engineering structures. Composite Structures, 2016. 153: p. 297-310.

7. Khalili, S.M.R., M. Najafi, and R. Eslami-Farsani, Effect of Thermal Cycling on the Tensile Behavior of Polymer Composites Reinforced by Basalt and Carbon Fibers. Mechanics of Composite Materials, 2017: p. 1-10.

8. Kim, R.Y., A.S. Crasto, and G.A. Schoeppner, Dimensional stability of composite in a space thermal environment. Composites science and tech-nology, 2000. 60(12): p. 2601-2608.

9. Li, H., et al., The effect of thermal fatigue on the mechanical properties of the novel fiber metal laminates based on aluminum-lithium alloy. Composites Part A: Applied Science and Manufacturing, 2016. 84: p. 36-42.

10. Nayfeh, A.H., Thermomechanically induced interfacial stresses in fibrous composites. Fibre Science and Technology, 1977. 10(3): p. 195-209.

11. Okba, S.H., et al., Effect of thermal exposure on the mechanical properties of polymer adhesives. Construction and Building Materials, 2017. 135: p. 490-504.

12. Qaiser, H., et al., Optimization of interlaminar shear strength behavior of anodized and unanodized ARALL composites fabricated through VARTM process. International Journal of Material Forming, 2015. 8(3): p. 481-493. 
13. Qin, Y. and S. He, Effects of thermal-mechanical cycling on microstructure and tensile properties of B/Al composite. Materials Science and Engineering: A, 2008. 472(1): p. 130-135.

14. Rawal, S.P., Metal-matrix composites for space applications. JOM Jour-nal of the Minerals, Metals and Mat-erials Society, 2001. 53(4): p. 14-17.

15. Rouquie, S., et al., Thermal cycling of carbon/ epoxy laminates in neutral and oxidative environments. Composites Science and Technology, 2005. 65(3): p. 403-409.

16. Russell-Stevens, M., R. Todd, and M. Papakyriacou, The effect of thermal cycling on the properties of a carbon fibre reinforced magnesium composite. Materials Science and Enginee-ring: A, 2005. 397(1): p. 249-256.

17. Wegman, R.F. and J. Van Twisk, Surface preparation techniques for adhesive bonding. 2012: William Andrew.

18. Yu, Q., et al., Effects of vacuum thermal cycling on mechanical and physical properties of high performance carbon/bismaleimide composite. Materials Chemistry and Physics, 2011. 130(3): p. 1046-1053.

19. Zhao, M., et al., Effects of thermal cycling on mechanical properties of AlNp/Al composite. Materials Lett-ers, 2004. 58(12): p. 1899-1902. 